\title{
The Greek Diaspora of Melbourne, Australia through the Eyes of the Second Generation Greek Australian
}

\author{
By Maria-Irini Avgoulas* \\ Rebecca Fanany ${ }^{\dagger}$
}

\begin{abstract}
Melbourne has a large and dynamic Greek community that began to form in the 1950s with migration to Australia in the years following the Second World War and the Greek Civil War. The elders of this community, in particular, have tried to ensure that their culture and traditions are kept alive and are handed down from generation to generation. The long history and cultural richness of the Greek tradition is a great source of pride to its members, and this is a key characteristic of the Greek community of Australia. Young and old Greek Australians speak of their country of origin with great pride and passion, as it remains central to their perception of nationality and ethnicity. This importance placed on the retention of the language and culture of their nation of origin means that cultural transmission across generations is of great significance to the community and can provide valuable insight into their interpretation of their own experiences. This paper will present findings from a three generation study about health beliefs and practices of women in the Melbourne Greek community. The experience of granddaughters, who represent the second Australian generation, and how they see their grandmothers' experience as migrants to Australia will be discussed. The impact of the Diaspora phenomenon and the creation of a Greek community in Melbourne will be considered in the context of health, memory, religion, Greek culture, food, and personal and group identity.
\end{abstract}

\section{Cultural Transmission and Maintenance of Identity}

The Assisted Passage Agreement made in 1952 between the Greek and Australia governments allowed for Greek people to migrate to Australia. This occurred post war, the time when Greece was occupied by the German- Italian forces during WWII and, following this, experienced a civil war that began a few months after the country was liberated. The civil war lasted from 1946-

\footnotetext{
*Associate Lecturer, School of Psychology and Public Health, College of Science, Health and Engineering and PhD Candidate, Deakin University, Australia.

${ }^{\dagger}$ Senior Lecturer in Indonesian, School of Humanities and Social Sciences, Deakin University, Australia.
} 
1949, resulting in a strongly anti-Communist government and alliance with NATO and the ideas of the west. For the many immigrants who decided to take the long journey from their homeland Greece to Australia, this move was a new start as Australia was seen as the 'lucky country,' a sentiment echoed by many of the immigrants.

It has now been many decades that this population has been calling Australia home. Despite this, these immigrants continue to invest heavily in maintaining their culture of origin and Greek way of life despite living in Australia. Kaloudis (2006) has noted that these immigrants have been able to maintain distinctive links to Greece that have connected them to their homeland and in turn offered them the feeling of belonging. Phinney, Horenczyk, Liebkind, and Vedder (2001) also note that the attitude of the immigrants in wanting to maintain their culture of origin and/ or acculturate to and, in turn, how much they want to become part of the new culture is also of importance. The process of change is never linear and transition is experienced differently from one person to the next. Similarly literature indicates that the experience of acculturation is best understood as a two dimensional process of preservation and adaptation, rather than a linear one, see, for example (Berry, 1990; 1997; La Fromboise, Coleman and Gerton, 1993; Nguyen et al., 1999; Sayegh and Lasry, 1993).

This Greek diaspora of Australia is now elderly and their offspring the $1^{\text {st }}$ generation [their children], the $2^{\text {nd }}$ generation [their grandchildren] and for some even a $3^{\text {rd }}$ generation [great-grandchildren] are too calling Australia home as they are Australian born citizens. These descendants have acculturated into mainstream Australian society but are still quite connected with their Greek origin. Literature indicates that particularly the children of these immigrants have a crucial connecting role between their parents who were born in another country and the community (Khoo, Mc Donald, Giorgas, and Birrell 2002). The reason for this, as illustrated by Portes (1994), is that they are the first generation born in another country to that of their parents, and this seems to determine whether certain aspects of their nation of origin will be maintained, such as language, traditions and identity. The reason being, taking the Greek Diaspora of Australia as an example, that they are the first generation that has been born and raised in another country to that of their parents. They have been educated in Australia and, in turn, their social environment has been influenced by the Australian culture, such as customs, behavior, food and the English language. Berry and Sam (1997) highlight that generally the preference for immigrants is to integrate by maintaining their culture but adjusting to the new one. This way they may be able to remain bicultural, still part of their culture of origin as well as the larger community. An example of this can be seen in cultural festivals, where various celebrations occur in traditional ways and may include dancing, food, music and culturally appropriate behavior for the new community that immigrants are members to (see, for example Humphrey and Humphrey 1988; Maglicco 1998). However, now there seems to be another avenue for immigrants to connect and maintain ties to their nation of origin. Findings by Panagakos (2003), studying the Greek community in Canada, 
show that technology is now playing a vital part in maintaining cultural identity. This research shows that communication via computers and television is an avenue for connection for these immigrants to their homeland and, as technology use spreads, it is also a way of connecting with Greek people worldwide and, in turn, this is a new option to maintain cultural identity.

\section{Retention of Language and Culture}

Retention of language is of great importance and also is a component of the acculturation process in the context of migration. Literature has indicated that language ability is also connected to the wellbeing of immigrants in areas such as finance, education and professions (Masgoret and Gardner 1999; Weston 1996). Another benefit in learning a new language when migrating is the ability to be bilingual. Alba, Logan, Lutz and Stults (2002) note that members of the immigrant generation in the Anglo-Saxon world may learn English; however, their language of choice, particularly at home with their family, tends to remain their native language. Research (see, for example Grinberg and Grinberg, 1989) shows the deep significance of the first language, as this language tends to hold early memories that are quite solid and resistant to change.

Culture is something that is learnt over time, something shared by members of the same cultural group and that can impact behavior and how experience may be understood and managed within a specific cultural/ethnic group. Culture is often transmitted between members of a particular group, generally from one generation to the next, by elders. This is not necessarily a deliberate act. It is a process that often happens over time and eventually become a part of who people are and the way they may think about things (Schonpflug, 2001). Generally, transmission of knowledge occurs in the areas of values, skills, behavior and knowledge. Language is a part of culture that may be transmitted.

Stevens (1992) argues that size and geographical segregation of a cultural group is of importance as a concentration of people that live close to one another provides greater opportunities to use their language of origin. Literature also indicates that there are factors such as social status, demography and institutional support that can enable or be a barrier to the maintenance of an ethnic language (Giles, Resenthal and Young 2010). For the Greek diaspora of Australia, and particularly the Greek people of Melbourne, this was something that did not challenge them as these criteria made it possible for them maintain the Greek language in Australia, due to the importance they ascribed to the cultural history of Greece and the large number of Greek people who migrated at the same time and became established in Melbourne. This established Greek community of Melbourne, as noted by Tsolidis and Polland (2010), set up of churches, schools, clubs for the elderly and young people, and cultural and sporting groups that have provided support and a means of connection for their members. 


\section{Background to the Study}

This research examined the health beliefs and practices in three generations of Greek Australian women in Melbourne. Each family contained three female members (immigrant, $1^{\text {st }}$ generation Greek Australian and $2^{\text {nd }}$ generation Greek Australia). A total of 16 families, 48 participants, took part in this study. The participants were all interviewed separately and were invited to discuss their understanding of health and illness in the context of their cultural background and personal experience. The interviews took place in reverse order of age, the younger generation first, followed by the mothers $\left(1^{\text {st }}\right.$ generation) and then the grandmothers (immigrant generation). As the aim of this research was to explore the transmission of health beliefs between the generations and the way they understand both health and disease as an aspect of cultural maintenance in the context of the larger Australian society, it was assumed that ideas about health rooted in the Greek culture derive in large part from the immigrant generation. For this reason, participants were interviewed in reverse order of age, assuring that the information provided was representative of their original thoughts, beliefs and conceptualizations and not influenced by their grandmother or mother who already knew what the interview was about.

Female participants were selected for this study as it has been suggested that grandmothers hold a vital position in the family, particularly when it comes to the maintenance of the community language. Greek families are seen by Pauwels (2005) and Georgas et al. (2006) as being quite traditional in the way they function and tend to maintain traditional family roles, such as women taking on the responsibility for caring for others. Because female family members in the Greek community generally take on the responsibility for the health of their kin, it was expected that transmission of health information between grandmothers, mothers and daughters is of special significance.

This paper highlights this and elucidates the importance placed on retention of language and culture of the nation of origin. The data presented is from the perspective of the $2^{\text {nd }}$ generation participants who took part in this study. These young women were aged between 16-18 years. All were born and raised in Australia and were of Greek background. Their grandmothers, who also took part in this study, had migrated from Greece and been living in Australia between 39-56 years. These participants come from a rural background in the Greek islands as well as from mainland Greece. Some of their places of origin include Samos, Thessalia, Kalamata, Kastoria, Crete, Chios and Thessaloniki.

\section{Findings and Discussion}

Decades following their migration, the immigrant generation seem to remember the Greece of their childhood. Their memories are filled with 
nostalgia for their homeland and, when they reminisce of Greece to their families, it is often in a very positive way. The experience of migration has been described by these grandmothers as a very difficult and challenging stage in their life. Their resilience however is notable, in how they were able to manage, adjust and adapt to and incorporate the Australian lifestyle. These participants described migration as very hard but they hoped to return to Greece. Yet, they managed to be successful in Australia and often admit that they would not have had many of the opportunities they enjoyed if they had remained in Greece. They have been successful in Australia as evidenced by the fact that many of them eventually brought houses and businesses and were able to send their children to school where they had to pay tuition.

The diaspora these immigrants created in Australia has proven to be a source of resilience and has enabled them to keep striving despite circumstances they found very difficult. Their resilience is visible in the fact they have incorporated many aspects of the Australian context into their daily life. Their children, the $1^{\text {st }}$ generation, are not distinguishable from other Australians from different backgrounds in terms of their ability to speak English, their kinds of career they have and their entrance into various professions, such as healthcare, law, education, government and politics.

The granddaughters of these immigrants describe their grandmothers' experience of migration in much the same way as their older relatives. Several noted that they currently are the age of the grandmothers when they migrated and were able to draw parallel between their experience. A common sentiment expressed by the elders of this community relates to the loss of family members they left behind, and this was echoed by granddaughters. "I think if you are around family you have more support," and "Migrating to Australia there is not much of that here, unless you have moved with family." They perceived that, even if their grandmother may not have had formal healthcare in Greece, she may have been healthier because of family support. This emphasises the importance of social connectedness to this community.

The grandmothers left Greece when living was very difficult and describe it as, "very bad," "a struggle after the war," "no food, no money, no healthcare (did not go to doctors)." Generally, this is the Greece that was described to these young women by their grandmothers. Most of them, however, have been to Greece, and the picture they saw is quite different. They note, "Everything is different to what they told me," and "They had painted a picture almost what to expect, but it was a long time since they had been, and it was a lot different." The younger women described Greece as modern and not as poor as their grandmothers implied, with computers, water and television.

The memories that the immigrants have shared with their children and grandchildren are of an older Greece, the Greece that they were raised in, and the one that holds their childhood memories. This is the Greece that they have tried to re-create in Melbourne. They are struggling to come to terms with the fact that Greece has now changed, as it is part of Europe now, and the people there have also had to change. This is the natural course of things, and they have changed as well, even if they do not realize it. For this reason, the Greek 
Diaspora often expresses its sorrow that they have been forgotten or that Greece and the Greek people have changed because the Greece they remember no longer exists.

The comments made and the sentiments expressed by these participants shows that they have preserved certain elements of Greece from their childhood. Changes that they have noted could be because of influences from the Australian mainstream and acculturation to the Australian lifestyle. As a country, Greece has changed, developed and evolved in different ways that they were not aware until recently. It would have been very difficult for them to know what Greece was like, unless they were there, despite what they hear on Greek television or read in the Greek newspaper. Their knowledge of modern European culture would also be limited as they have lived in Australia for decades and they may be unaware how this European culture may have impacted Greece.

These immigrants maintain and have transmitted to the younger generation a static perception of Greece and the Greek people, and they expected to find things as they had left them. Over the decades since the Greek diaspora migrated to Australia, the Greek community of Melbourne has also changed and evolved. In a sense, the immigrants and their descendants have re-created an old Greece from the memories of the elders. What has formed in Melbourne, for this diaspora group, can be described as a separate Greek Australian identity from that of the Greek identity in Greece. There has been a split between these two groups that are both Greek but that are culturally different. Despite there being differences between the Greek people in Australia and the Greek people in Greece, being connected is of great significance for the diaspora. The younger generation has learned this attitude as well, as they feel, want and need to be part of their ancestral homeland. Some said about Greece, "It's like going home."

The maintenance of these links is quite exceptional and, in a sense, has provided all the generations of the Greek diaspora of Melbourne with a sense of belonging (see, for example Kaloudis, 2006). For the young, in particular, whose Greek identity is completely second hand and is based heavily on the memories of an older generation, advances in technology are now reinforcing their sense of identity. The use of smart phones, iPad, Skype, Viber and Facebook are new, affordable and frequent means for communication and the maintenance of their cultural identity worldwide (see, for example Panagakos, 2003). In Melbourne, many older members of the Greek community, often at the urging of children and grandchildren, have adopted these forms of communication and are injecting new cultural knowledge from Greece today into the Melbourne community. Despite the fact that it comes through older relatives, younger people are learning more about Greece and its current society in this way.

There are four distinct aspects of cultural identity that define all generations of the Greek community in Melbourne- religion, language, food and culture. The immigrants made enormous efforts to maintain and hand down their Greek culture and, in many ways, have rejected what they view as 
"Australian." The younger members of the community tend to maintain these views, even as they participate in institutions their grandmothers perceive as "Australian," as despite the fact that they are far more fluent in English and familiar with Australian culture. Many of the younger members of the Greek community repeat their grandmothers' sentiments about food and state that they prefer Greek food to other types of cuisine. They also tend to believe it is healthier, not just for them, but in a universal sense. In this, the cultural centrism of the immigrant generation is easily visible. It is not possible to assess the extent to which the younger members of the community act on such ideas. However, they express them freely and claim to prefer what they see as their heritage diet, even when they do not eat these foods on a daily basis.

Many of these young women rely on Greek terms when discussing the food they associate with their heritage culture. These include, ко ó $\sigma 00 \pi \alpha$

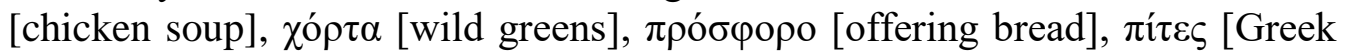
pies], and $\varphi v ́ \lambda \lambda o$ [filo pastry]. They also spoke of Greek food tasting different and better in Greece than Australia and suggested that produce was healthier and organic in Greece. These comments were similar to the sentiments echoed by the grandmothers and were likely learned from them. One young participant said, "Processed food is bad for our health, all the chemicals. Why are our apples so big now? Apples from the tree are smaller compared to the ones from the supermarket. The growth hormones, they didn't have that, and that's the reason why we have more illnesses today, that we didn't have them in my grandmother's time." These comments can be seen as a repetition of comments made by the grandmothers based on their memories of an idealized Greece, the Greece they maintain in memory and tried to re-create in Melbourne.

Language in particular is a key marker of identity for the $2^{\text {nd }}$ generation. They associate see the Greek language as essential to their Hellenic identity They all wanted to hold on to this but were aware that language is very difficult to maintain and requires a great deal of personal initiative. The interviews with the $2^{\text {nd }}$ generation were mostly conducted in English, as they are more able to express their thoughts and views in the English language. While they switched to Greek at times during the interview, particularly when they spoke of their Greek experiences and their families, culture, the Greek Orthodox religion and Greek food, they are not fluent speakers of Greek and often cannot use more than isolated words and phrases

For the $2^{\text {nd }}$ generation of the Greek diaspora, culture is made up of day to day practices, such as values, beliefs, the role of fate and destiny, supernatural beliefs such as the evil eye and magic and even traditional health beliefs that have withstood the test of time and that they feel set them apart from other Australians. Some traditional health beliefs known to the granddaughters of the Greek diaspora include, "I always have tea $\chi \alpha \mu \rho \mu \eta \lambda_{1}$ [chamomile] with honey; honey has a lot of healing qualities to it," "butter on burns," "Once my brother

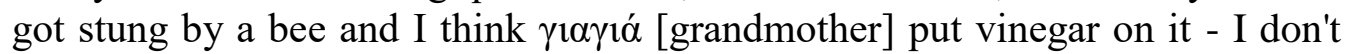
know why," "They would put natural Greek yogurt to fill out their hair, you put natural Greek yogurt in your hair, you leave it in as a treatment and it fills your hair out, it's for hair loss." When asked to relate any home remedies they 
knew, these young women expressed certain terms in Greek, including terms of address. For many of them, it is these individual words, for which they do not use an English equivalent, that are the main visible markers of Greek identity.

This illustrates the shift in cultural orientation that has occurred in the Greek community in Melbourne. Their grandmothers are Greeks living in an English speaking environment. The granddaughters are Australians with a few personal elements of Greek culture. However, the home remedies they knew are significant because of the source. They trust their grandmothers implicitly, and, for this reason, accept the validity of the health information transmitted to them. One participant said, "There are some home remedies that we will use. My grandmother would cut up an onion and she would put it in a cup. She would put a bit of honey and a teaspoon of sugar, leave it overnight in the fridge so in the morning it has produced a cold juice. It's sweet but it still tastes like onion, and you drink it, and it makes your sore throat go away. I have done this heaps of times, and it's soothing because of the honey. It's like having a teaspoon of honey." This participant's mother also mentioned the same remedy showing the vital role the first generation has in maintenance of cultural identity, as noted in the literature (see, for example Khoo, Mc Donald, Giorgas, and Birrell 2002; Portes 1994). Secondly, these young women often commented that Greek things they learn or things they know come from their grandmothers. However, these elements of culture have been part of their day to day life that were reinforced by their parents, and this is an important part of the maintenance and transmission of cultural identity.

Their Greek Orthodox faith is another marker of Greek identity in Melbourne. The significance of their faith as a source of resilience and social support is a major aspect of the cultural perspective transmitted by grandparents to granddaughters. Unlike their grandmothers, the members of the $2^{\text {nd }}$ generation were all educated (either completing high school or at university). However, the informal support provided to them by their faith seems to be as important as formal healthcare and medicine. God, religion, prayer, miracles and the sacraments of the Church provide them with comfort, support, resilience and emotional wellbeing. The importance of religion as a means of coping is well documented in the literature see, for example Pargament (1997). These young women often use Greek words (because these are terms they do not use an English equivalent for) when they speak of the

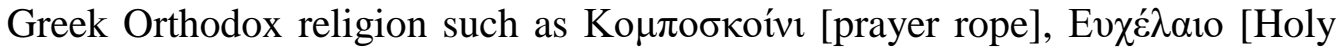

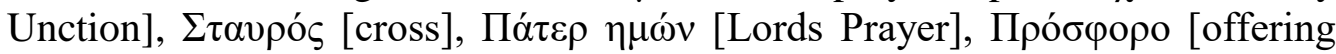

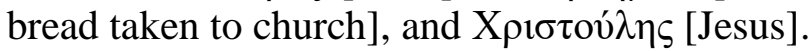

In all of these areas, the activities and ideas of the grandmothers can be seen to have contributed to the sense of Greek identity of the granddaughters. Their self-perception as members of the larger Greek community is underpinned by limited use of the Greek language but can be seen as deriving from the perceptions of the original immigrant generation and the aspects of cultural it felt most important. For the younger generation, this input, combined with their own experience in Australia, has created a unique diaspora identity that is significantly different from that of Australians from other backgrounds, 
despite the obvious similarities shared by all Australians of this generation and supported by English as the primary language of communication.

\section{Conclusion}

The Melbourne Greek community started forming decades ago from when the Greek immigrants started to migrate in the 1950's. Cultural maintenance was vital for the immigrants, and their goal was for the Greek culture and way of life to be maintained in their new home. Their descendants -- children, grandchildren and for some even great grandchildren - inherited the same attitude towards cultural maintenance. Religion, language, food and culture were of great importance across the generations. The immigrants remain concerned how long their descendants will be Greek and fear a time will come when they will become Australian. A similar concern has now been raised by their granddaughters, as they too seem worried about how long they will be able to hold on to the knowledge, values and way of life taught to them by the elders of their family and how much of this culture they will be able to transmit to their children. Only time will tell what the Greek community of Melbourne will be like in the next 50 years and whether it manages to remain distinct from the Australian cultural mainstream.

\section{References}

Alba, R., Logan, J., Lutz, A., and Stults, B., 2002. Only English by the Third Generation? Loss and Preservation of the Mother Tongue among the Grandchildren of Contemporary Immigrants. Demography, 39(3), pp. 467-484. doi:10.1353/dem.2002.0023.

Berry, J., 1990. Psychology of acculturation. In: J. Berman Ed., Nebraska Symposium on Motivation 37. Lincoln, NE: University of Nebraska Press. pp. 201-234.

Berry, J., 1997. Immigration, acculturation and adaptation. Applied Psychology: An International Review, 46, pp. 5- 68.

Berry, J., and Sam, D. 1997. Acculturation and adaptation. In J. Berry, M. Segall, and C. Kagitcibasi Eds. Handbook of cross-cultural psychology: Vol. 3. Social behavior and applications. Boston: Allyn and Bacon. pp. 291-326.

Georgas, J., Berry, J.W., van de Vijver, F.J.R., Kagitcibasi, C., and Pootinga, Y.H. 2006. Families across cultures: A 30-nation psychological study. New York: Cambridge University Press.

Giles, H., Rosenthal, D., and Young, L. 2010. Perceived ethnolinguistic vitality: The Anglo- and Greek-Australian setting. Journal of Multilingual and Multicultural Development, 6(3-4), pp. 253-269. doi:10.1080/01434632.1985.9994206.

Grinberg, L., and Grinberg, R. 1989. Psychoanalytic perspectives of migration and exile. New Haven,CT: Yale University Press.

Humphrey, T. C. and L. T. Humphrey, ed. 1988. We Gather Together: Food and Festival in American Life. Ann Arbor, MI: University of Michigan Press. 
Kaloudis, G. 2006. Greeks of the diaspora: modernizers or an obstacle to progress? International Journal on World Peace. Available at: < http://www.highbeam. $\mathrm{com} / \mathrm{doc} / 1 \mathrm{G} 1-158528228 . \mathrm{html}$.

Khoo, S.-E., P. Mc Donald, D. Giorgas, and B. Birrell. 2002. Second Generation Australians. Canberra: Australian Centre for Population and the Department of Immigration and Multicultural and Indigenous Affairs.

LaFromboise, T., Coleman, H., and Gerton, J. (1993). Psychological impact of biculturalism: Evidence and theory. Psychological Bulletin, 114, 395-412.

Magliocco, S., 1998. Playing with Food: The Negotiation of Identity in the Ethnic Display Event by Italian Americans in Clinton, Indiana. In: Barbara G. Shortridge and James R. Shortridge, ed. The Taste of American Place: A Reader on Regional and Ethnic Foods. New York: Rowman and Littlefield.

Masgoret, A., and Gardner, R., 1999. A causal model of Spanish immigrant adaptation in Canada. Journal of Multilingual and Multicultural Development, 20, pp. $216-$ 235.

Nguyen, H., Messe, L., and Stollak, G., 1999. Toward a more complex understanding of acculturation and adjustment: Cultural involvements and psychosocial functioning in Vietnamese youth. Journal of Cross-Cultural Psychology, 30, pp. $5-31$.

Panagakos, A., 2003. Downloading New Identities: Ethnicity, Technology, and Media in the Global Greek Village. Identities, 10(2), pp. 201-219. doi: 10.1080/107028 90304326.

Pargament, K. I. 1997. The Psychology of Religion and Coping: Theory, Research, Practice. Guilford Press.

Pauwels, A., 2005. Maintaining the Community Language in Australia: Challenges and Roles for Families. International Journal of Bilingual Education and Bilingualism, 8(2-3), pp. 124-131. doi:10.1080/13670050508668601.

Phinney, J. S., Horenczyk, G., Liebkind, K., and Vedder, P., 2001. Ethnic Identity, Immigration, and Well-Being: An Interactional Perspective. Journal of Social Issues, 57(3), pp. 493-510. doi:10.1111/0022-4537.00225.

Portes, A., 1994. Introduction: immigration and its aftermath, International Migration Review, 28 (4), pp. 632-639.

Sayegh, L., and Lasry, J.-C., 1993. Immigrants' adaptation in Canada: Assimilation, acculturation, and orthogonal identification. Canadian Psychology, 34(1), pp. 98109.

Schönpflug, U., 2001. Cultural transmission - A Multidisciplinary Research Filed. Journal of cross-cultural Psychology 32(2). pp. 131-14.

Stevens, G., 1992. The Social and Demographic Context of Language Use in the United States. American Sociological Review 57, pp. 171-85.

Tsolidis, G., and Pollard, V., 2010. Home Space: Youth Identification in the Greek Diaspora. Diaspora, Indigenous, and Minority Education, 4(3), pp. 147-161.

Weston, R., 1996. English language skills and parents' well being. Family Matters, 45, pp. 34-37. 